\title{
CHRONOS SICKNESS: DIGITAL REALITY IN DUNCAN JONES'S SOURCE CODE
}

\begin{abstract}
The advent of digital technologies unquestionably affected cinema. The indexical relation and realistic effect with the photographed world much praised by André Bazin (2005) and Roland Barthes (1986) is just one of the affected aspects. This article discusses cinema in light of the new digital possibilities, reflecting on Steven Shaviro's consideration of "how a nonindexical realism might be possible" (Postcinematic 63) and how in fact a new kind of reality, a digital one, might emerge in the science fiction film Source Code (2013) by Duncan Jones.
\end{abstract} Keywords: Science Fiction Film; Post-postmodernism; Source Code; Digital Cinema

This article analyzes how the recent science fiction film Source Code (2013) by Duncan Jones has been shaped by new theoretical concepts in what critical theory has called the post-cinematic (Steven Shaviro, 2010), the pseudo-postmodern (Alan Kirby, 2006), the supercinema (William Brown, 2013), the new new Hollywood (Thomas Elsaesser, 2009), the post-filmic (Garrett Stewart, 2007), or even the post-postmodern (Linda Hutcheon, 2002). Contemporary science fiction films appear to have a distinct approach to postmodern aspects as nostalgia, dystopia and emphasis on space, as Fredric Jameson (1984), Linda Hutcheon (1989) and Andreas Huyssen (1986) argued. Previous science fiction films focus on a notion of the present period and emphasize concepts of time in their narrative construction and cinematic resources. New digital possibilities appear to be its main cause.

In analyzing Source Code, I expect to demonstrate how its representation of time reflects on the ontological relation between reality and digital reality, as it constructs a different concept of time within the science fiction genre. Such duality is possible through the elaboration of a virtual world, which allows existence beyond one's own body, time and space. Captain Stevens, the main character, confronts his disabled condition and dystopic world, reconfiguring the digital, and not the future, into a utopic possibility.

Shaviro explains that in post-cinematic films, "plot is no longer stabilized by temporal progression ... the 'new cinema'-as innovative as it is involuntarily caught up in historical change-has arrived at a point of temporal crisis where 'chronos is sickness itself"' (Postcinematic 166-7). Chronology becomes a disease. Chronos sickness emerges in an iterative present, which is haunted by the past and defies the future, while a malleable and multiple space predominates. The consequences of this sick chronos is a mind-game story (Elsaesser 19), which reiterates Garrett Stewart's argument that the digital form has affected the narrative content (Framed 173). This article begins discussing space, moves to the portrayal of technology and how it relates to our contemporary digital world, and finishes with the subject of time. 


\section{Data Worlds}

Source Code tells the tale of the American soldier Captain Colter Stevens (Jake Gyllenhaal), who is trapped in what seems to be a spaceship cabin or a training room. Within this room, he talks to his instructor Captain Colleen Goodwin (Vera Farmiga) through a video chat; she puts him in a virtual simulation (sim). His mission is to discover the bomber of a train before it explodes. Every time he fails, the bomb explodes, and Goodwin sends him back to the beginning of the simulation. But Captain Stevens is not comfortable in this apparent training section, he wants to leave it, and soon discovers that, despite being virtual, its consequences can still be real.

Different layers of virtuality compose space in Source Code. The narrative reveals three main layers of existence, which superimpose and fold into each other; they correspond to the different realities Captain Stevens finds along the film. The first is Captain Goodwin's control room. The second is where Captain Stevens is locked in what looks like a spaceship cabin, the capsule. The third is the simulation where the latter travels to, the train. This convoluted space tricks our understanding of what is real in this film. The virtual worlds of the simulations challenge the characters' and the viewers' mapping of reality.

The control room is where "reality" seems to be manifested, since this is the supposed real world. Captain Goodwin is part of a USA military program that invented a kind of time travel machine, the Source Code. This device is further discussed in the next section. Captain Goodwin's space looks more like a surveillance room than a scientist's laboratory, as the many screens behind her show. The idea of surveillance pervades the film as she is constantly watching and monitoring Captain Stevens, applying memory tests and exercises on him.

Interestingly, Captain Stevens's perspective predominates in the beginning of the film, which means that we only see Captain Goodwin through the small screen on the capsule. We are watching her, instead of the other way around. This inversion is the first foreshadowing of this film's mind-game construction.
More interesting is that the capsule where Captain Stevens is trapped is not real, being a virtual reality created by the program Source Code. Another inversion is that the real world where Captain Goodwin is located appears only on the virtual image of the screen in the virtual reality of the capsule.

The story is that Captain Stevens is actually in a coma. His body is incubated in a machine, while his mind is projected into the capsule by the Source Code, and then again in the train. A virtual simulation inside a virtual simulation. In this third space, he has to discover the bomb and the bomber. But as he says "This looks so real" (00:12:05), that it is hard for him not to get involved with the characters and events of the train simulation. This notion of reality is relevant because the fact that the capsule is also virtual is only revealed much later in the story. The viewer and the main character believe that the capsule is real while the train is virtual.

Comparing these two simulations leads us to a different understanding, another inversion in which the train looks real, while the capsule looks odd. The train's aesthetic is very realistic. The only uncanny feeling is the repetitions, since Captain Stevens always awakes in the same situations, as Phil (Bill Murray) in Groundhog Day (1993). Christina Warren (Michelle Monaghan) is talking to the Captain, the ticket collector comes and a woman spills coffee on his shoe. He is also a different person, as he embodies a man named Sean Fentress (Frédérick De Grandpré). In the train sequences, the Hollywood editing concepts studied and defined by David Bordwell predominate, lighting is realistic, shots follow the main character's perspective, and establishing shots orient us; some cuts are fast but they are recognizable within the space. The characters are on a moving train.

On the other hand, the capsule is surreal. He wakes up upside down with Captain Goodwin's voice already giving him instructions. A lack of medium or establishing shots contributes to the viewers' disorientation, while a close-up on his face and a dark lighting do not allow us to discover the surroundings. We receive as little information as he does about this second space. A filter makes the colors paler and bluish, because the main light source is Goodwin's screen. As 
the sequence proceeds the camera itself seems to be entrapped in this capsule, and cannot find the distance to open its lens and reveal more.

This difficulty in distinguishing the virtual and the real complicates space. As much as the main character, we are cheated into believing that the capsule is real, even though it looks odd, and that the train is a simulation that looks too real. But ultimately, neither is real. The twist of this mind-game film is to transform the ontology of these two virtual worlds into possible realities, as when Captain Stevens dies in the control room but survives in the train world by the end of the film.

The capsule goes under a transformation that relates to the instabilities of Captain Stevens's mind. The director Duncan Jones explains that at first "we designed the pod to resemble a helicopter cockpit. It's a small, intimate environment where he has this bright white screen in front of him that he can't really see through" (qtd. in Fordham 54). In this first instance, he is belted to a chair as a pilot. As he starts suspecting the nature of this cockpit, it starts collapsing as well, a lot of fluid is leaking and the heating stops working. When Captain Stevens discovers that the capsule is a virtual projection of his mind, it expands around him into a big, although restrictive space.

Duncan highlights that "at that point, the pod environment is supposed to resemble a medieval prison cell with a window up at the top throwing light on him, like something out of an old Errol Flynn movie. Colter [Captain Colter Stevens] ends up thinking of himself as being in a kind of virtual prison" (qtd. in Fordham 59). In this scene, the camera begins with a close-up on his face, and opens the frame going upwards as the cell grows, enhancing the mentioned prison feeling. A single light beam focuses part of his body, which works as a foreshadowing, since later we discover that he is disabled in the control room world, and the light emphasizes exactly what remains of his real body. Exposed wires, rust, and dirt makes the capsule look unstable and unsafe, which also recalls Captain Stevens's disabled body and comatose state. This transformation of the space exposes its connection to the character and his body, being as malleable as his understanding of reality.
When Captain Stevens discovers that he is trapped in these layers of simulations, he asks Captain Goodwin to disengage him from the Source Code. He wants to die, so that he would not be manipulated again, he says "Any soldier I have served with could say that one death is service enough" (00:51:32). Touched by his appeal, she confronts her superior, Dr. Rutledge (Jeffrey Wright), and disengages Captain Stevens from the machine. But she does this while the latter's mind is attached to the train reality because he wants to have a last 8-minutes with Christina, with whom he fell in love. When he dies in the control room, his mind survives in the train in Sean's body.

After his immigration from real to virtual, the train is no longer a virtual world but a parallel reality, with another Captain Goodwin and another version of his own body. He actualizes the virtual reality. As a consequence, the control room world becomes just another layer in a complex chain of existence. Similar to the replicants in Blade Runner, if the copy is as real as that which is copied, then they are all real. To turn virtual into real, space becomes malleable; because it cannot constrain as Things to Come's Everytown, it rather has to allow changes. At first, the virtual scenarios, the capsule and the train are addendums to a stable reality and its hidden layers. Finally, these layers become foldable sheets of space and existence for the characters.

Crucially, this space is not the fragmented postmodern space, as Blade Runner's "synthesis of mental architectures" (Bruno 67) that evokes a collision of cultures. Instead it is malleable, and such trait originates in the digital possibilities. A symbolical frame is when Captain Stevens and Christina are already safe in the alternative train reality. They stand in front of the Cloud Gate, popularly known as the Bean sculpture, in Chicago. This city does not look different, only distorted. The sculpture is a giant globe shaped metal structure with a bean format, which, through its mirrored view, folds the city image, thus making space malleable. And if we look carefully, we can see that the reflection of Captain Steve's shows another man, because this is more than another version of the city, it is also a different body. 


\section{Invisible Machines}

The Source Code is in the core of the film's narrative, but we never actually see this machine, only its tricks. Such invisibility complies with the digital configurations of recent technologies, which attempt to look as natural as possible-think about I-pad devices and their interfaces. In the control room, there are plenty of computer screens that monitor Captain Steven, and there is the incubator machine where he is kept alive, but no exceptional visual device stands out. Source Code no longer focuses on the machines, as the female robot in Metropolis, the surveillance eye in 12 Monkeys and the replicants in Blade Runner; rather it focuses on its illusions.

Although not markedly visible, the Source Code still impacts the film's narrative. This technology allows the discussed malleability of space, creating two levels of simulation, firstly the capsule, which englobes the second, the train. Its illusions interfere with the main character's identity. Captain Stevens's body becomes as malleable as space. In the capsule, it is not his real body, but a mind projection. Confused he asks: "What about the rest of my body? I can see my hands and my feet. They still move". But Captain Goodwin reports that "They are just a manifestation. They are just a way of making sense of all this" (00:48:45). In the train, he embodies Sean's body, as a ghost. To Stewart, Captain Stevens's body is "a remote control cyberpresence" (Framed 124). He looks at himself in the mirror and sees the passenger. The layers of virtual worlds get confused, and the character cannot recognize or find himself anymore. Captain Stevens is not simply a time traveler; he travels into a different body-almost as a spirit he uncannily possesses somebody.

Such uncanny aspect agrees with Stewart's argument that recent films have appealed to time travel narratives with a fantastic twist (Framed 173). This change constructs the digital more as a supernatural form than as a technology, as if this technology is still uncanny for us, similar to the tales in which photographs would trap the souls of the humans. Although this does not seem to be exactly the case in Source Code, there is an uncanniness in the lack of explanation to how we can create a parallel reality and survive in someone's else body. New technologies are indeed science fiction's utmost marvel and threat: robot-Maria in Metropolis, the replicants in Blade Runner, the digital/virtual world in Source Code. Furthermore, this desire of projecting oneself and believing the virtual to be real reflects the very contemporary technology of role-playing games.

Role-playing games (RPG) as World of Warcraft (WOW) or God of War function by projecting the players into an avatar, a character in the game. The players are physically in a different reality (in their rooms in front of their computers), and they project themselves through the character they create into a different world. The immediacy in these games lies in their first-person perspective. Thus, despite the necessary mediation of the computer or video game, the individual is able to have a virtual experience that is quite immediate. As Bolter and Grusin argue "the viewer should forget that she is in fact wearing a computer interface and accept the graphic image that it offers as her own visual world" (316). The media needs to be immersive "which means that it is a technology of mediation whose purpose is to disappear" (Bolter and Grusin 315).

Technology is in fact a strong point in the film's hypermediacy. Bolter and Grusin explain that hypermediacy is the heterogeneous characteristic of digital media, the screen within a screen, and the combination of different and random media (315). An example is how Captain Goodwin appears through a screen to Captain Stevens, creating the illusion that she is in the virtual reality and not him. And behind her, other screens, that open minor windows, and these screens within the framed screen pose the question of how many more virtual realities can be unfolded in theses frames.

Shaviro explains that this relation between video game-also television, video, and digital-and film convey the "structure feeling" of the post-cinematic affect. Source Code strongly appeals to the role-playing experience. The players, as is the case with Captain Stevens, become someone else in this different reality; in the case of World of Warcraft, you can be a wizard, an orc, a dwarf, an elf, a female or male; in God of War, you are Kratos, a Spartan demigod warrior looking for revenge. In both, the gamers have some freedom 
to choose their actions; missions and objectives exist but they can be skipped, delayed, or even ignored. The former is called a massively multiplayer online roleplaying game (MMORPG), due to its massive quantity of players, whose interactions with other players may have different motivations from accomplishing missions to simply making friends.

The popularity of these games unveils their power in relation to the consuming public. The Guinness World Record gave the record to World of Warcraft as the most popular subscription-based MMORPG in 2010 for having over 12 million subscribers around the world. ${ }^{1}$ God of War is not as popular as WOW, but its long saga confirms its popularity-God of War II, God of War III, God of War: Chains in Olympus, and God of War: Ghost in Sparta. Many other names can be mentioned here, as contributors to the popularity of games in which the player assumes a first-person role in a virtual reality, Doom, Counter Strike, Diablo, Battlefield, Fallout, to mention a few.

Besides the relation to the video game mode, Source Code is also a mind-game film, as Elsaesser defines it. The spectator within Captain Stevens is immersed in the layers of virtuality, or reality, and has to unveil the secret behind the bomb. Every time Captain Stevens dies, he is revived in the capsule chamber, which is a striking reminder of games like Counter Strike or Half Life, in which every time the players die, they are back to the base, where they can refuel, recharge and go back killing. This repetitive mode illustrates Elsaesser's explanation of "new forms of spectator-engagement and new forms of audience-address" (16). According to Elsaesser, the old forms of voyeurism, in which in classic cinema the spectator only watches passively, are not appealing anymore. Recent films engage the spectator in more than voyeurism since they immerse into a corporeal cinema.

Through a social critical perspective, Source Code portrays the scenario of terrorism fear, which recalls $9 / 11$, as the main character is a soldier who died in Afghanistan. On the other hand, more than terrorism, I suggest that fear arises from the loss of reality, as the main character is unable to distinguish which reality is real, as Stewart writes "That's the real paranoia now: that there's never been anything really there" (Framed 145).

Source Code's problematization of the Afghanistan War does not relate to space, but to the body. Captain Stevens is kept alive in an incubation room. He only has half of his body, and his body perception is part of the simulation incited by the computer program. He is in a state of a semi-consciousness or coma, which is maintained by this technology from the Source Code. This character is the contemporary hero, soldier, and time travel man. Quite differently from Cabal in Things to Come and Cole in Twelve Monkeys, Stevens does not have an astronaut suit; he does not even have a complete body, only the fair simulation in a computer projection, which is only part of his own brain.

Claudia Springer describes a kind of new sci-fi hero: "rampaging muscle-bound cyborgs were replaced by slim young men and women jacked into cyberspace, inspired by 'console cowboys' in cyberpunk fiction of the 1980s" (in Alien Zone II 204). But Captain Stevens is more than a geek specialist; he becomes a virtual ghost. In Source Code, it is not the city that is degraded and hopeless but the person in itself. When the film's perspective changes from Captain Stevens to Captain Goodwin, the spectator realizes how mistaken the main character is about his own being and condition. Even his voice is only green letters on Goodwin's computer; he never really spoke in the story. Stevens is a ghost, a shadow of his own past, his consciousness existing in the virtuality of Goodwin's computer.

In this utter video game, digital world, the human transcends the body and transforms the mind into data, which can be transferred and uploaded, as Dr. Rutledge says "let's clear his memory and reinitialize Source Code" (01:12:45). The body, which was copied in Metropolis, replicated in Blade Runner and reconstructed in RoboCop, loses meaning, in as much as space. What remains is the numeral data of Captain Stevens's memory in the digital world.

\section{Chronos Sickness}

Source Code's narrative exemplifies how Chronos is sick of its own chronological nature, as in Shaviro's 
argument. Time becomes multiple, the past hunts the present, the latter is an annoying iteration and the future can finally be confronted. The digital as a theme and a technology plays a major role in this multifaced time.

That the past can haunt the present is no news. Captain Stevens, for instance, hears sounds of war-bomb explosions, missiles, helicopters and radio transmissions (00:02:31)-when awaking for the first time in the train simulation. But Source Code complicates this statement. To Stewart, this film's postwar trauma is resolved through a multiple time in a postmortem environment ("War" 124). The past experience of the Afghanistan war lingers in his present as post-war trauma, one that apparently cannot be forgotten. But the film complexifies the idea of past, since the Source Code allows Captain Stevens to travel through a victim's last 8 minutes of memories. Memories work as time travel tickets. In inhabiting Sean's body and interacting with his memories, Captain Stevens makes someone's past into his present, to reconstruct his future. Once more, we can compare him to a ghost possessing Sean's past as his present.

Time is also reconfigured from a linear doomed plot, into a utopian alternative reality. The train that Captain Stevens saves in the end of the film has already exploded. Captain Goodwin repeatedly tells Captain Stevens that he cannot change the bomb explosion, because it has already happened and it is a memory. She explains that "what you experienced was a shadow, an after image of a victim on a train. This is real life. Here ... the program was not designed to alter the past, it was designed to affect the future" (01:07:15). Nonetheless, he manages to realize this virtual past into a parallel reality, transforming past and virtual into a new dimension, bifurcating time, and creating Stewart's multiple time (Framed 124).

He also gives the past a new ontology. He saves the past; so it seems he changed the past, but this is actually a different reality. As he explains "you thought you were creating eight minutes in a past event, but you were not, you've created a whole new world" (01:26:21). In fact, the past is not only not simply virtual, not an image of what had happened, and it is much more than nostalgia; it is somewhen, we cannot only alter, but ultimately inhabit, a reality in itself.
Captains Stevens's present is a continuous repetition, as a video game resettling. Trapped in the Source Code, he is repeatedly sent back to Sean's last 8 minutes of memory, until he realizes that "it's the same train but it's different" (00:11:42). In this difference, he finds the possibility to change Chronos's linear course, to make things different. Through his iterative present, he saves Christina, discovers about his death in the Afghanistan war, makes amends with his father, and saves the train.

This repetition may initially imply the cyclical boredom of suburban life in the train that is always late and crowded. Christina describes: "they [the passengers] are all so utterly... normal. That's what's so terrifying about them" (00:22:45), and when the also incredible ordinary looking bomber is asked why, he can only answer "because the world is hell" (01:01:13). Terror is in the repetition of this prosaic existence, an iteration that explodes and can only be utopic if, as Captain Stevens and Christina-she has just changed her life by quitting a job and boyfriend-one finds a different track to the same train. Because this might also be a parallel to the Afghanistan war that has no significant explanation or justification. In this sense, terrorism is inscribed in the ordinary commuters' everyday life from the suburbs to Chicago.

When the present repeats itself, the past collides with the future. Captain Stevens travels into Sean's memories, confronts the future bomber, who has not yet detonated the bomb. The hero of the past is combating the enemy of the future (Stewart "War" 124). The latter trespasses its unreachable characteristic. In the end of every 8 -minute memory cycle, for example, Captain Stevens and the train explode, and in transitioning from the train back to the capsule, flash mixed images appear. One of these images is the Bean sculpture, which only appears by the end of the story, a foreshadowing and an anachronism.

The future is no longer a distant one-hundred-years from now, as in Things to Come. It is already contained in the past and the present with no meaning attached to them, as in a computer game. Layers of time equal the digitalized images. As space in the digital world, time is meaningless-what really matters is the sheer sensation of the game, to start over again. 
Future also happens soon, if not now. The images of contemporary Chicago already construct an idea of future, progress, and even utopia, with its skyscrapers, highways, and modernly designed buildings. Similar to Blade Runner or 12 Monkeys, the city is an existing reference, which increases the appeal for a contemporary audience. At the same time, the future is hopeless in a scenario in which postwar becomes postmortem. Stewart believes that "this dystopian fantasy can certainly not be alleviated by its anodyne resolution in a prevented civilian threat" (124), because of the illusions of the Source Code, in which Captain Stevens's own voice and body are only projections of his mind. His future can be better only because he changes his own body, space and time.

In the last train simulation, Captain Stevens quickly saves the train, calls his father, and kisses Christina in their last minute. When his time is over, Captain Goodwin turns off his incubator, and when the bomb usually explodes, it does not. But time seems to stop. The image is frozen and the tracking camera slowly passes through the still passengers. This delay scene stops narrative and invites Mulvey's pensive spectator, who reflects not only on the story but on the film's technological resource, the digital immersion. This scene is also closer to Gunning's cinema of attractions, in which the image has no narrative function, but it is simply exhibitionist. In addition, Brown argues that this kind of construction recalls the camera's time, since "the camera makes visible its own temporality" (98). This narrative break enforces extra-diegetic elements, because this freeze moment is when Captain Stevens transcends a technology into an unexplainable parallel world, and when the spectator dismisses the story to immerse into the digital technology.

In Source Code, narrative follows a logical organization, the hero is in trouble, he finds a solution, he changes his future. To find his happy end, time is complicated, since chronology is more malleable. The parallel worlds create alternative timelines and multiply space, present is iterative, past is relived and future is changed. As Dr. Rutledge says "Source code is not time travel, rather Source Code is time reassignment, it gives us access to a parallel reality" (00:34:36). Stewart summarizes that in recent war films: "[w]e're asked to believe that computer science can overcome the laws of duration itself and recuperate lost time in a parallel universe, turning digital surveillance into electronic transcendence" ("War" 122-3). ${ }^{2}$

Source Code demonstrates its profound assimilation of the virtual idea, in which even the physical body is abandoned and the human migrates to different forms of existence in distinct times and spaces. The film's utopia is digital, because the characters' final realization is due to an immersion into the virtual world, and not due to an advancing into the future or a recuperation of something lost in the past. This assimilation of the digital into the film's narrative and structure results into the malleability of space and a non-linear or not-fixed time. The parallel universe of Source Code challenges notions of rigid space construction in cinema, which corroborates Steven Shaviro's postcinema, in that continuity rules have exploded and their violations are no longer a surprise. In this postpostmodern film, technology is still essential, although not as a main issue rather as a granted part of society. New machines are not items to be feared, instead they integrate life and their resolution is not bad or good, only consequential. This position towards technology also relates to the scientific fascination with technology and an investment in special effects, which culminate in the digital form changing the narrative content. In such context, time is virtual and detached from chronological constraints, offering new narrative possibilities. I also want to point to Brown's argument that all films show different temporalities, but the digital enhances this idea (96). The presence of digitalization as theme and form radicalizes the possibility of multiple times.

\section{Notes}

1. See the website: <http://www.guinnessworldrecords. com/records-6000/most-popular-subscription-basedmassively-multiplayer-online-role-player-game(mmorpg)/> Accessed in 20/11/2012.

2. Source Code's title was translated as Contra o Tempo in Portuguese, which in English would translate as "against time." This mistranslation dismisses time as digital or multiple, and only focuses on the train reality, where Captain Stevens fights against time. At the same time, 
it highlights the video-game intensity of repetition and time constraints. The original title advances a view of reality that can be changed; source code allows a great number of options to be constructed and, if needed, to reconstruct certain software. In this sense, the original title reinforces the idea of a possibility of rewriting one's history, of starting again, of reconfiguring, and in doing so, tailoring new possibilities.

\section{References}

Barthes, Roland. "The Reality Effect." 1968. The Rustle of Language. Oxford: Blackwell, 1986. 141-48.

Bazin, André. "The Evolution of the Language of Cinema." 1967. What is Cinema? Vol. 1. Berkeley, Los Angeles, London: University of California Press, 2005. 23-40.

Bellour, Raymond. “The Pensive Spectator." Wide Angle, 9.1 (1987): 6-10.

Bolter, Jay David; Grusin, Richard. "Remediation." Configurations 4.3 (1996): 311-58.

Bordwell, David. The Way Hollywood Tells It. Berkeley, Los Angeles and London: University of California Press, 2006.

Brown, William. Supercinema: Film-Philosophy for the Digital Age. New York and Oxford: Berghahn Books, 2013.

Bruno, Giuliana. "Ramble City: Postmodernism and 'Blade Runner."' October 41 (Summer, 1987): 61-74.

Burgoyne, Robert. "Film Narratology”. New Vocabularies in Film Semiotics. Orgs. Robert Stam, Robert Burgoyne and Sandy Flitterman Lewis. London: Routledge, 1992. 70-124.

Corseuil, Anelise. "Film Beyond Boundaries: Film, Migrant Narratives and Other Media." Ilha do Desterro. 51 (Jul./Dez. 2006): 09-17.

Elsaesser, Thomas. “The Mind-Game Film.” Puzzle Films: Complex Story Telling in Contemporary Cinema. Warren Buckland ed. Chichester: Wiley-Blackwell, 2009. 13-41.

Fordham, Joe. "Reality Deconstructed." Cinefex. 126 (Jul. 2011): 40-67.

Hutcheon, Linda. "Postmodern Afterthoughts." Wascana Review of Contemporary Poetry and Short Fiction 37.1 (2002): 5-12.

The Politics of Postmodernism. London and New York: Routledge, 1989.

Huyssen, Andreas. After the Great Divide: Modernism, Mass Culture, Postmodernism. Bloomington and Indianopolis: Indiana University Press, 1986.
Kirby, Alan. "The death of post-modernism and beyond"; Philosophy Now 58, (2006). <http://philosophynow. org/issues/58/The_Death_of_Postmodernism_And_ Beyond $>$ Set. 5, 2013.

Kuhn, Annette. Alien Zone II: The space of science fiction cinema. London and New York: Verson, 1999.

Jameson, Fredric. Archaeologies of the Future: The Desire Called Utopia and Other Science Fictions. Verso: London and New York, 2007.

"Postmodernism, or the Cultural Logic of Late Capitalism." New Left Review 1.146 (Jul-Aug. 1984): 53-92. 2 Jul. 2010. <classweb.gmu.edu/sandrew3/misc/ nlr142jameson_postmodernism.pdf>

Mulvey, Laura. Death $24 x$ a Second: Stillness and the Moving Image. London: Reaktion Books, 2006.

Shaviro, Steven. "Post-continuity: full text of my talk." The Pinocchio Theory. 26/03/2012 < http://www.shaviro. com/Blog/?p=1034> 20/08/2014.

. Postcinematic Affect. Ropley, UK: 0-books, 2010.

Stewart, Garrett. Framed Time: Towards a Postfilmic Cinema. Chicago and London: University of Chicago Press, 2007.

"War Pictures: Digital surveillance from foreign theater to homeland security front." The Philosophy of War Films. David LaRocca Ed. Lexington, Kentucky: The University Press of Kentucky, 2014. 107-32.

Recebido em: 04/05/2016 Aceito em: 06/06/2016 